\title{
Facile green synthesis of gold nanoparticles with gum arabic as a stabilizing agent and reducing agent
}

\author{
Chien-Chen Wu and Dong-Hwang Chen* \\ www.goldbulletin.org
}

\begin{abstract}
A facile, completely green, and cheap route for the synthesis of Au nanoparticles at $25-75^{\circ} \mathrm{C}$ has been developed by using only hydrogen tetrachloroaurate as the precursor and gum arabic (GA) simultaneously as a reducing agent and a stabilizing agent. No extra reagents are needed. From the analyses of UV/VIS absorption spectra, TEM, HRTEM, SAED, and XRD patterns, the formation of Au nanoparticles with a fcc structure was recognized. The synthesis reaction was usually finished in 2-4 $\mathrm{h}$. Increasing the reaction temperature increased the formation rate but had no significant effect on the optical property and size of Au nanoparticles. With increasing $\mathrm{Au}$ (III) ion concentration or GA concentration, the mean diameter of Au nanoparticles slightly increased. Also, the particle size distribution became broader at higher $\mathrm{Au}(\mathrm{III})$ ion concentration or lower GA concentration due to the insufficient protection. Although raising the GA concentration was helpful to reduce $A u(I I I)$ ions completely and stabilize the Au nanoparticles, too high GA concentration was not suitable for the stabilization of $\mathrm{Au}$ nanoparticles because the increased intermolecular force of GA might hinder the dispersion of Au nanoparticles. Furthermore, the resultant $\mathrm{Au}$ nanoparticles were found to remain highly stable in the $\mathrm{NaCl}$ solution.
\end{abstract}

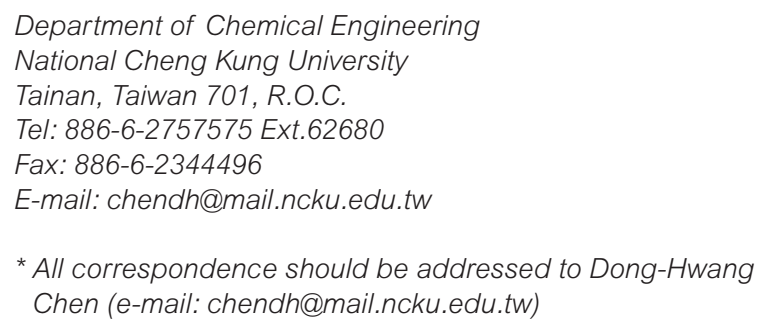

Keywords: gold, nanoparticles, gum arabic, green synthesis

\section{Introduction}

Among various metal nanoparticles, gold (Au) is the most widespread material used in optics, electrochemistry, catalysis, and biochemical sensing because it is stable, less toxic and biocompatible [1-4]. A lot of techniques have been developed for the synthesis of Au nanoparticles. However, it is inevitable that the interventions of environmentally harmful and toxic chemicals interfere in the synthesis procedures of Au nanoparticles.

Recently, the green synthesis or fabrication of $\mathrm{Au}$ nanostructures have been considerably studied by using harmless alternative biocompatible molecules such as proteins, peptides, cellulose, soybeans, gellan gum, vitamin B2, starch, and D-glucose as stabilizing or reducing agents [5-14]. We also developed a facile route for the synthesis of $\mathrm{Au}$ nanoparticles by the use of food additives [15].

In this study, we proposed another environmentally benign process for the synthesis of Au nanparticles using gum arabic (GA) as both the stabilizing agent and reducing agent. GA is known as a natural and harmless polysaccharide derived from acacia trees. Due to its well steric stabilization effect as adsorbing on the surfaces of colloids and its numerous functional groups such as carboxylate and amine groups, it has been widely used as emulsifiers and capping agents [16-22]. In addition, it is also known that GA consists of mainly three distinctive fractions which are referred as arabinogalactan (AG, 88.4\% of the total) with a low protein content $(0.44 \% \mathrm{~W} /$ $w$ ), arabinogalactan-protein (AGP, $10.4 \%$ of the total) with a high protein content of $9.18 \% \mathrm{w} / \mathrm{w}$, and glycoprotein (GP, about $1 \%$ of the total) with a protein content of 50\% w/w [23-24]. Since the amino acids which are commonly considered as the reducing agents [25-27] are present in AGP and AG fractions, we synthesized Au nanoparticles by the reduction of 
$\mathrm{Au}(\mathrm{III})$ ions with $\mathrm{GA}$ as both the reducing agent and stabilizing agent in the absence of other additives.

\section{Materials and methods}

Hydrogen tetrachloroaurate $\left(\mathrm{HAuCl}_{4} \cdot 4 \mathrm{H}_{2} \mathrm{O}\right)$ was purchased from Alfa Aesar (Ward Hill, MA). Gum arabic (molecular weight: $\sim 250,000$ ) was obtained from Fluka (Buchs). The water used work was the reagent-grade water produced by Milli-Q SP ultrapure-water purification system of Nihon Millipore Ltd., Tokyo. For the synthesis of Au nanoparticles, hydrogen tetrachloroaurate $(0.1,0.3,0.5,0.7$, and $0.9 \mathrm{mM}$ ) was dissolved in aqueous solutions of GA $(1,5,10,15$, and $20 \mathrm{mg} / \mathrm{ml})$ at first. Then, the solutions were stirred gently at the desired temperatures $\left(25,40,55\right.$, and $\left.70^{\circ} \mathrm{C}\right)$ to yield $\mathrm{Au}$ nanoparticles. The typical sample was obtained at a $\mathrm{Au}(\mathrm{III})$ ion concentration of $0.3 \mathrm{mM}$, a GA concentration of $10 \mathrm{mg} / \mathrm{ml}$, a temperature of $55^{\circ} \mathrm{C}$, and a reaction time of $4 \mathrm{~h}$.

The UV-VIS absorption spectra of the resultant colloid solutions were monitored by a JASCO model V-570 UVNIS/NIR spectrophotometer. The particle size analysis by transmission electron microscopy (TEM) was done using a Hitachi model HF-2000 field emission transmission electron microscope with a resolution of $0.1 \mathrm{~nm}$. The electron diffraction pattern and lattice image were performed by a Jeol model JEM-2100F electron microscope operated at 200kV. $X$-ray diffraction (XRD) measurement was performed on a Shimadzu model RX-III X-ray diffractometer at $40 \mathrm{kV}$ and $30 \mathrm{~mA}$ with CuK $\alpha$ radiation $(\lambda=0.1542$ $\mathrm{nm})$. Fourier transform infrared (FTIR) spectrum was recorded on a Varian FTS 1000 FT-IR Spectrometer. The samples for XRD and FTIR measurements were washed twice with water, collected by centrifugation, and vacuum dried overnight. The measurement of hydrodynamic diameter distribution by dynamic light scattering (DLS) was conducted on a Malvern Autosizer model 4700/PCS100 spectrometer equipped with an $\mathrm{Ar}$ ion laser operating at 488 $\mathrm{nm}$. All the colloidal solutions obtained at various parameters were found to have a $\mathrm{pH}$ value around 4 and used for DLS analysis without $\mathrm{pH}$ adjustment.

\section{Results and discussion}

\section{Characteristics of GA-stabilized Au nanoparticles}

Fig. 1 shows the UV-VIS absorption spectra of the resultant $\mathrm{Au}$ colloid solutions obtained at a $\mathrm{Au}(\mathrm{III})$ ion concentration of $0.3 \mathrm{mM}$, a GA concentration of

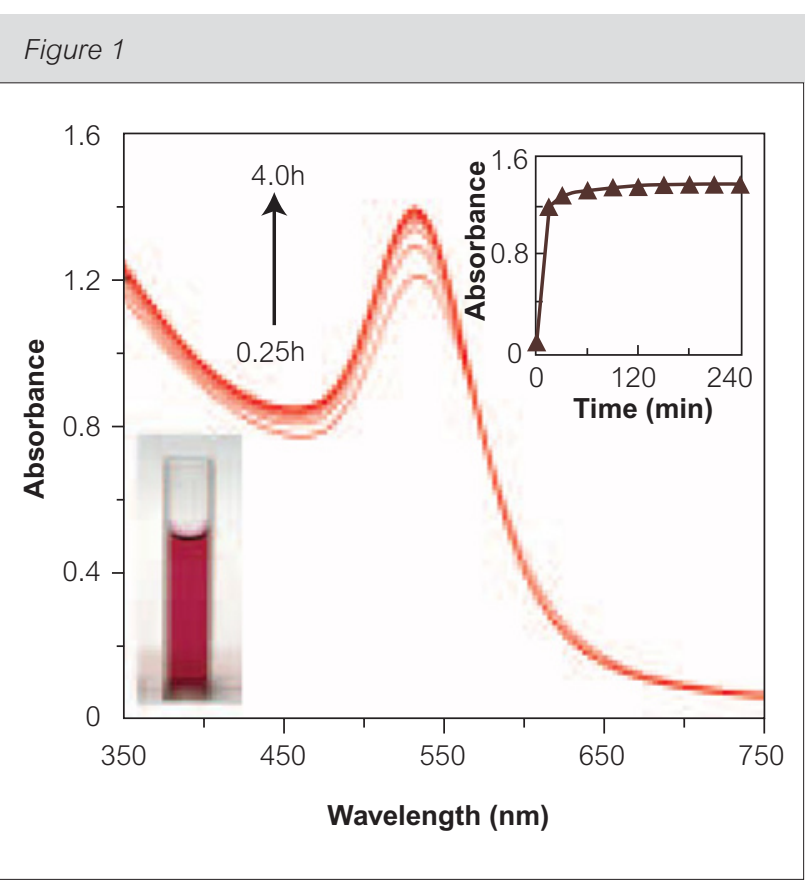

UV-VIS absorption spectra of the resultant Au colloid solutions obtained at a $\mathrm{Au}(\mathrm{III})$ ion concentration of $0.3 \mathrm{mM}$, a $\mathrm{GA}$

concentration of $10 \mathrm{mg} / \mathrm{ml}$, and a temperature of $55^{\circ} \mathrm{C}$ for various time intervals. The bottom left inset shows that the resultant colloid solution is wine red and transparent. The top right inset indicates the time-dependence of the absorbance at $532.5 \mathrm{~nm}$

$10 \mathrm{mg} / \mathrm{ml}$, and a temperature of $55^{\circ} \mathrm{C}$ for various time intervals. The characteristic absorption band of Au nanoparticles was clearly observed at 534.5$532.5 \mathrm{~nm}$, slightly blue shifted with time. Also, as indicated in the bottom left inset of Fig. 1, the colloid solution was wine red and transparent, consistent with the UV-VIS absorption spectra and revealing that the Au nanoparticles were well dispersed. Both results suggested that $A u$ nanoparticles have been successfully synthesized. In addition, the top right inset of Fig. 1 shows that the absorbance at 532.5 $\mathrm{nm}$ increased sharply within $0.25 \mathrm{~h}$ and approached a constant after about $2 \mathrm{~h}$, implying the synthesis reaction was finished at this time.

The TEM image for the typical sample obtained at a $\mathrm{Au}(\mathrm{III})$ ion concentration of $0.3 \mathrm{mM}$, a GA concentration of $10 \mathrm{mg} / \mathrm{ml}$, a temperature of $55^{\circ} \mathrm{C}$, and a reaction time of $4 \mathrm{~h}$ was shown in Fig. 2(a). It is obvious that the resultant $\mathrm{Au}$ nanoparticles were discrete completely with a mean diameter of $21.1 \pm 4.6 \mathrm{~nm}$, revealing that GA could protect Au nanoparticles from aggregation effectively. The hydrodynamic diameter distribution of GA-stabilized Au nanoparticles in water was shown in Fig. 2(b). The hydrodynamic diameters were mostly in the ranges 


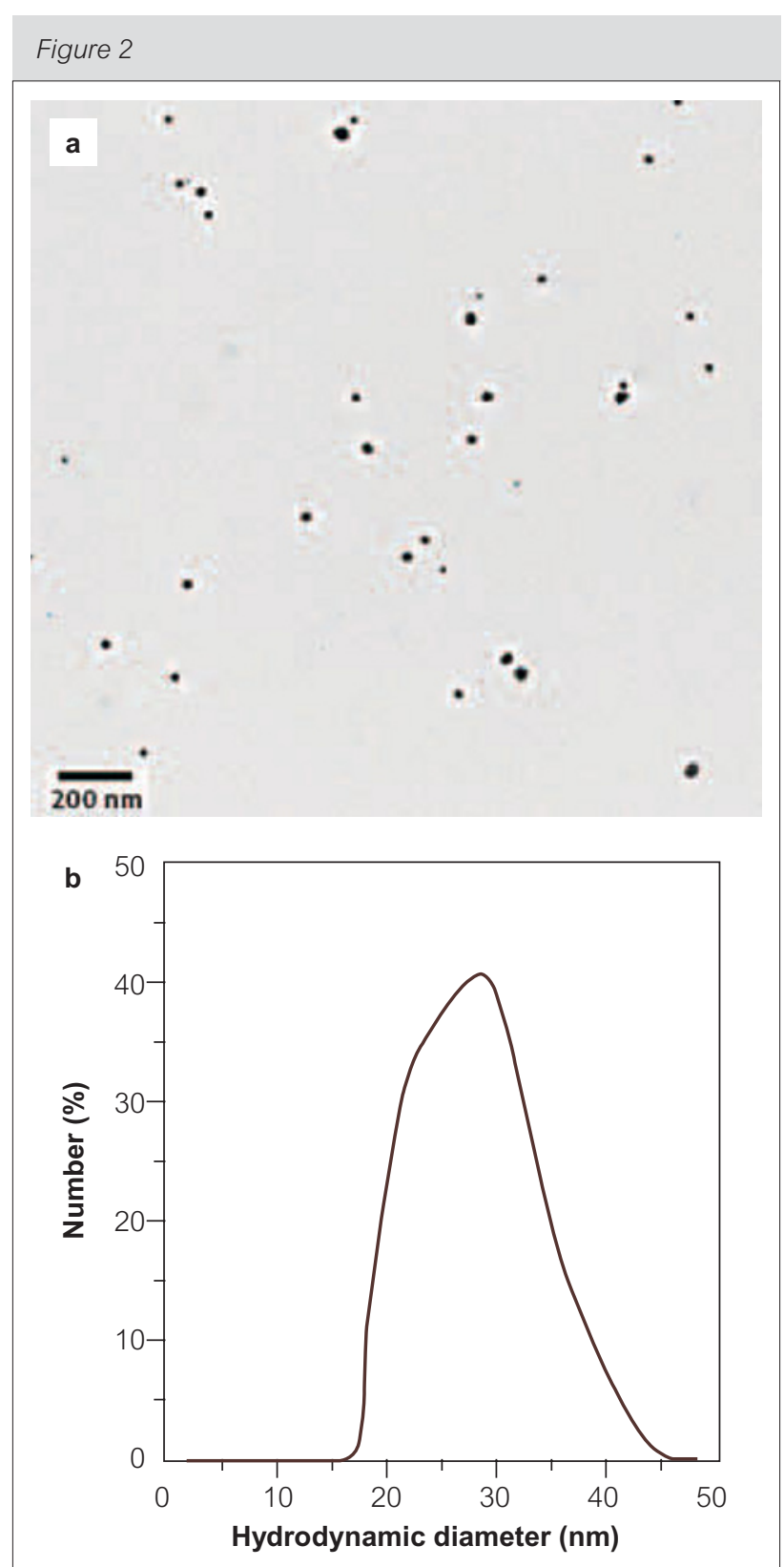

TEM image (a) and hydrodynamic diameter distribution (b) for the typical sample obtained at a Au(III) ion concentration of $0.3 \mathrm{mM}$, a GA concentration of $10 \mathrm{mg} / \mathrm{ml}$, a temperature of $55^{\circ} \mathrm{C}$, and a reaction time of $4 \mathrm{~h}$

of $16-45 \mathrm{~nm}$ with a mean hydrodynamic diameter of $26.8 \pm 5.3 \mathrm{~nm}$, which was roughly consistent with that from TEM observation. Furthermore, the high-resolution TEM (HRTEM) image as shown in Fig. 3(a) revealed that $\mathrm{Au}$ nanoparticles had a high crystallinity and the lattice spacings of 2.04 and $2.35 \AA$ related to the (200) and (111) planes of face centered cubic (fcc) Au. The selected-area electron diffraction (SAED) pattern was shown in Fig. 3(b), in which the radii of four main fringe

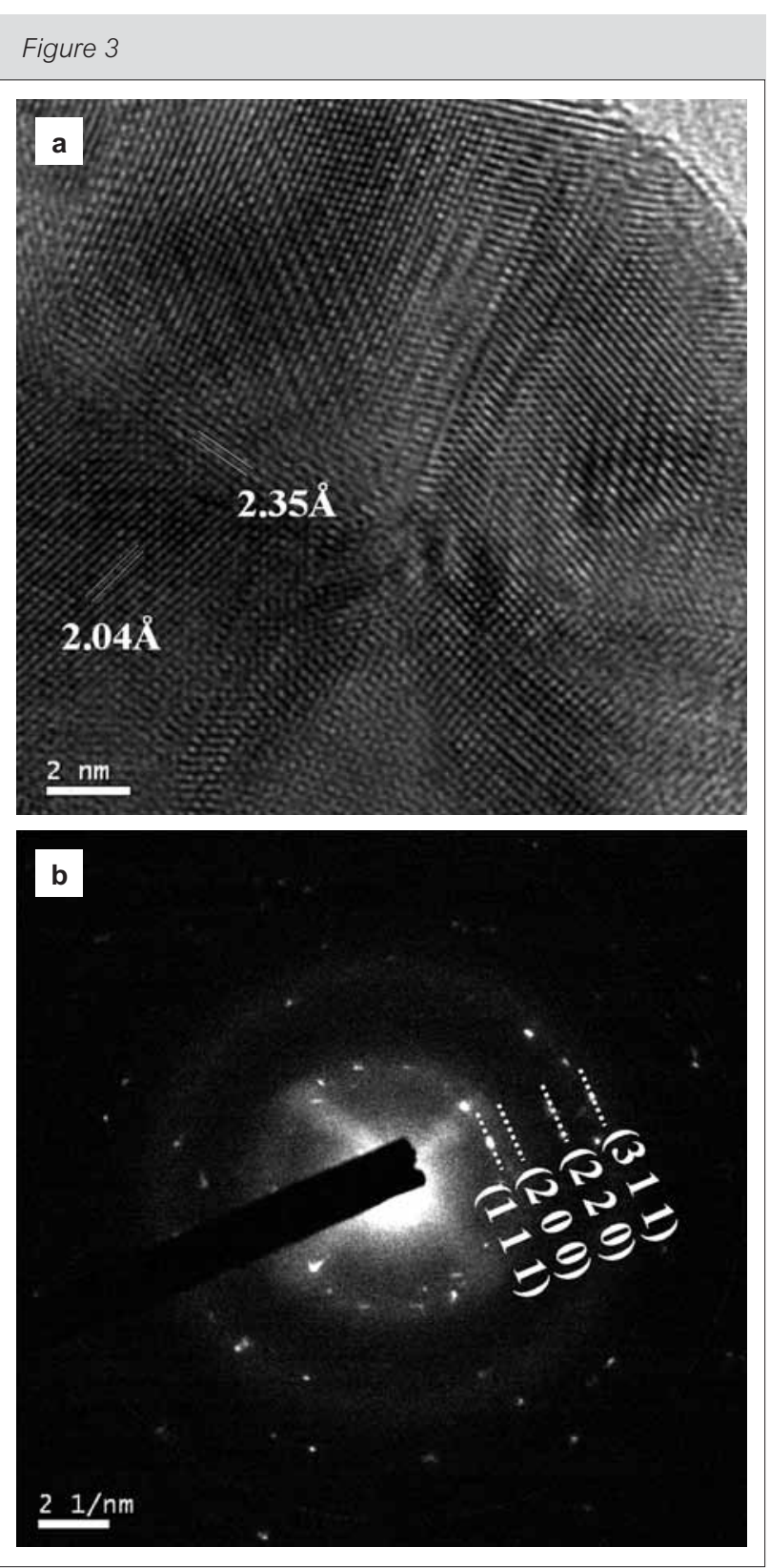

HRTEM image (a) and SAED pattern (b) for the typical sample obtained at a Au(III) ion concentration of $0.3 \mathrm{mM}$, a GA concentration of $10 \mathrm{mg} / \mathrm{ml}$, a temperature of $55^{\circ} \mathrm{C}$, and a reaction time of $4 \mathrm{~h}$

patternswere in the ratio of $\sqrt{3}: 2: \sqrt{8}: \sqrt{11}$. They related to the (111), (200), (220), and (311) planes of fcc Au. Fig. 4 indicates the XRD pattern of Au nanoparticles. Four characteristic peaks at $2 \theta=38.1,44.3,64.5$, and $77.4^{\circ}$ which were corresponding to the (111), (200), (220), and (311) planes confirmed that the resultant Au nanoparticles had the fcc structure. The above results all demonstrated the formation of Au nanoparticles. 


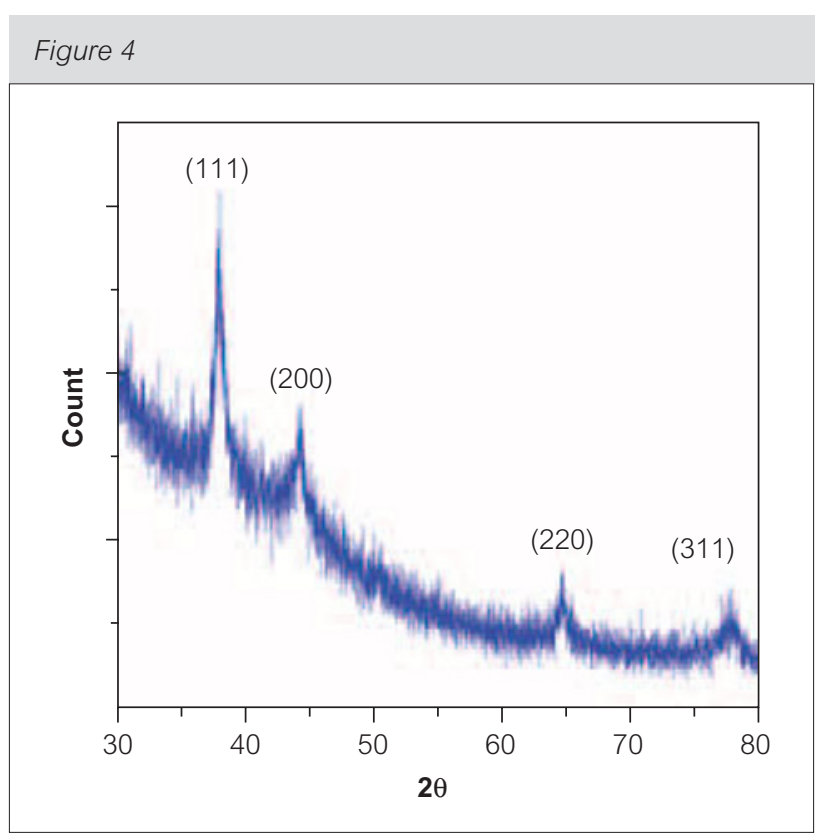

XRD pattern for the typical sample obtained at a Au(III) ion concentration of $0.3 \mathrm{mM}$, a GA concentration of $10 \mathrm{mg} / \mathrm{ml}$, a temperature of $55^{\circ} \mathrm{C}$, and a reaction time of $4 \mathrm{hrs}$

\section{Effects of reaction temperature and $\mathrm{Au}(\mathrm{III})$ ion and GA concentrations}

Fig. 5(a) shows the time-dependence of the absorbance at $532.5 \mathrm{~nm}$ for the resultant $\mathrm{Au}$ colloid solutions obtained at various temperatures with a $\mathrm{Au}(\mathrm{III})$ ion concentration of $0.3 \mathrm{mM}$, a $\mathrm{GA}$ concentration of $10 \mathrm{mg} / \mathrm{ml}$, and a reaction time of 4 h. It was found that, with increasing the temperature, the formation rate of $\mathrm{Au}$ nanoparticles increased but the characteristic absorption band had no significant shift as shown in the inset of Fig. 5(a), implying the resultant Au nanoparticles had similar size in the examined temperature range. This could be confirmed by the TEM analysis as shown in Figs. 2(a) and 5(b)-(d).

Fig. 6(a) shows the UV-VIS absorption spectra of the resultant Au colloid solutions obtained at various $\mathrm{Au}(\mathrm{III})$ ion concentrations (0.1-0.9 mM) with a GA concentration of $10 \mathrm{mg} / \mathrm{ml}$, a temperature of $55^{\circ} \mathrm{C}$, and a reaction time of $4 \mathrm{~h}$. It was obvious that, with increasing the $\mathrm{Au}(\mathrm{III})$ ion concentration, the absorbance at $532.5 \mathrm{~nm}$ increased linearly (the inset in Fig. 6(a)) but the characteristic absorption band was slightly red-shifted. Also, when Au(III) ion concentration was $0.9 \mathrm{mM}$, a longitudinal plasmon which might be resulted by the larger particle size or particle aggregation was observed around 620 $\mathrm{nm}$. By further TEM analysis, the effect of $\mathrm{Au}(\mathrm{III})$ ion concentration on the mean diameter of $\mathrm{Au}$

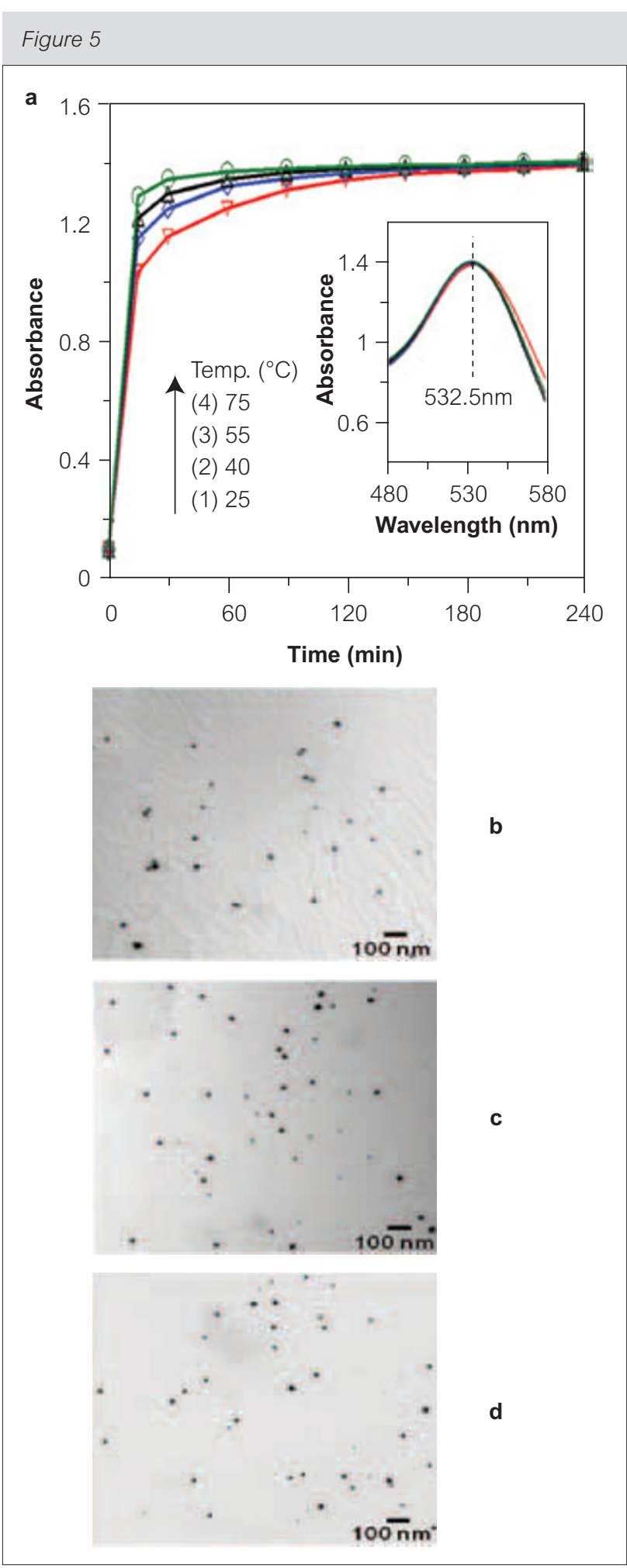

Time-dependence of the absorbance at $532.5 \mathrm{~nm}$ for the resultant Au colloid solutions obtained at various reaction temperatures (a) and the corresponding TEM images obtained at 25 (b), 40 (c), and 75 (d) ${ }^{\circ} \mathrm{C}$. The inset in (a) indicates the UV-VIS absorption spectra focused around $532.5 \mathrm{~nm}$. The reaction time was $4 \mathrm{~h}$ and the $A u(I I I)$ ion and GA concentrations were $0.3 \mathrm{mM}$ and $10 \mathrm{mg} / \mathrm{ml}$, respectively 
nanoparticles could be illustrated in Fig. 6(b). It was found that the mean diameter increased slightly with the increase in $\mathrm{Au}(\mathrm{III})$ ion concentration. This could be due to the higher collision frequency among $\mathrm{Au}$ atoms or nuclei. When $\mathrm{Au}(\mathrm{III})$ ion concentration was $0.9 \mathrm{mM}$, significantly larger particle size and size distribution were observed. This might be referred to the less protective effect by GA and could account for the longitudinal plasmon around $620 \mathrm{~nm}$ as shown in Fig. 6(a).

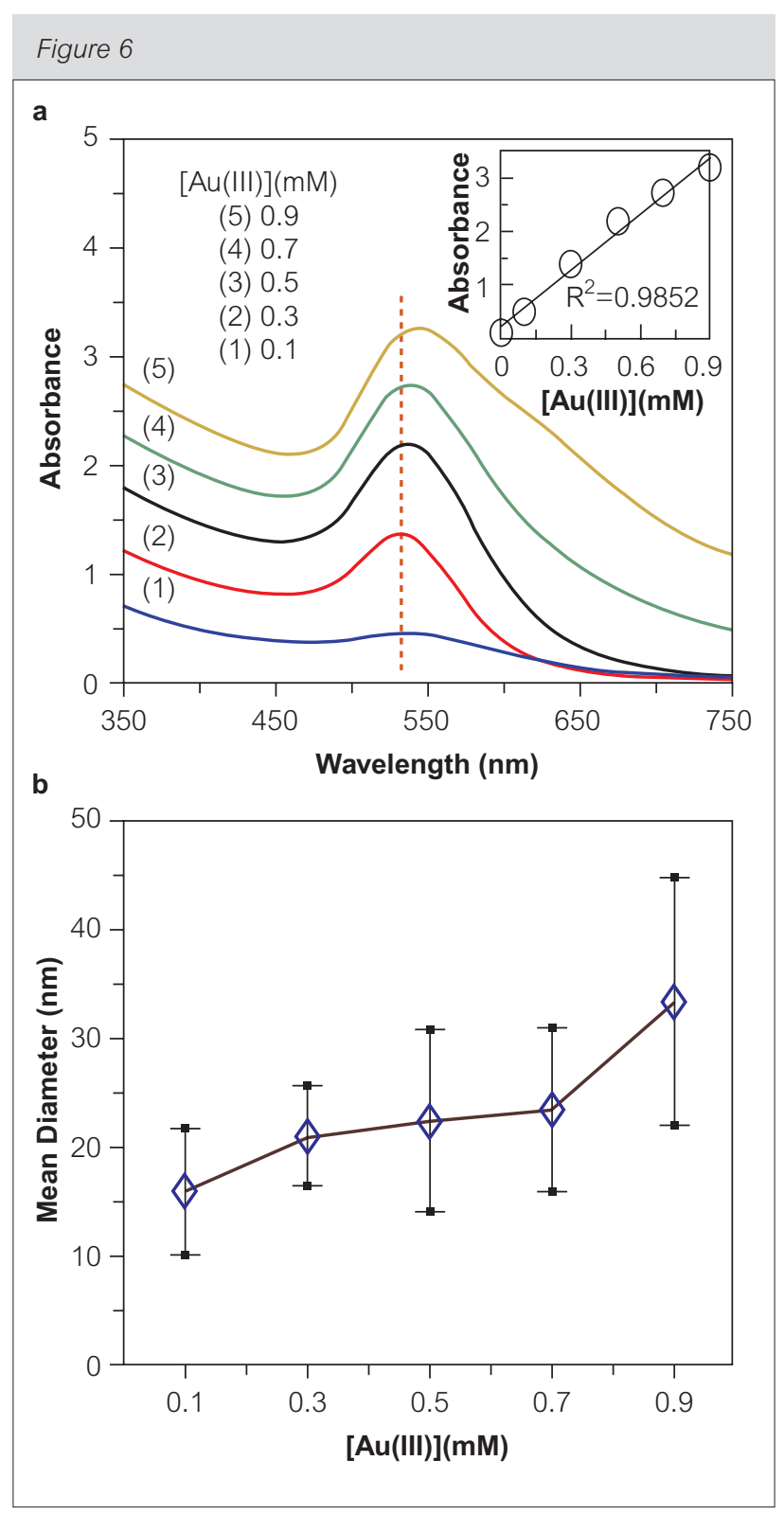

(a) UV-VIS absorption spectra of the resultant Au colloid solutions obtained at a GA concentration of $10 \mathrm{mg} / \mathrm{ml}$, a temperature of $55^{\circ} \mathrm{C}$, and a reaction time of $4 \mathrm{~h}$ for various $\mathrm{Au}(I I I)$ ion concentrations. The inset indicates the effect of $\mathrm{Au}(I I I)$ ion concentration on the absorbance at $532.5 \mathrm{~nm}$. (b) Variation of mean diameter with $\mathrm{Au}(\mathrm{III})$ ion concentration
Fig. 7(a) shows the UV-VIS absorption spectra of the resultant Au colloid solutions obtained at various GA concentrations $(1-20 \mathrm{mg} / \mathrm{ml})$ with a $\mathrm{Au}(\mathrm{III})$ ion concentration of $0.3 \mathrm{mM}$, a temperature of $55^{\circ} \mathrm{C}$, and a reaction time of $4 \mathrm{~h}$. When GA concentration was as low as $1 \mathrm{mg} / \mathrm{ml}$, it was found that the resultant $\mathrm{Au}$ colloid solution was purple-blue. Also, its absorption band became weak and broad with a red shift to about $578 \mathrm{~nm}$ (the inset in Fig. 7(a)). This suggested that the low GA

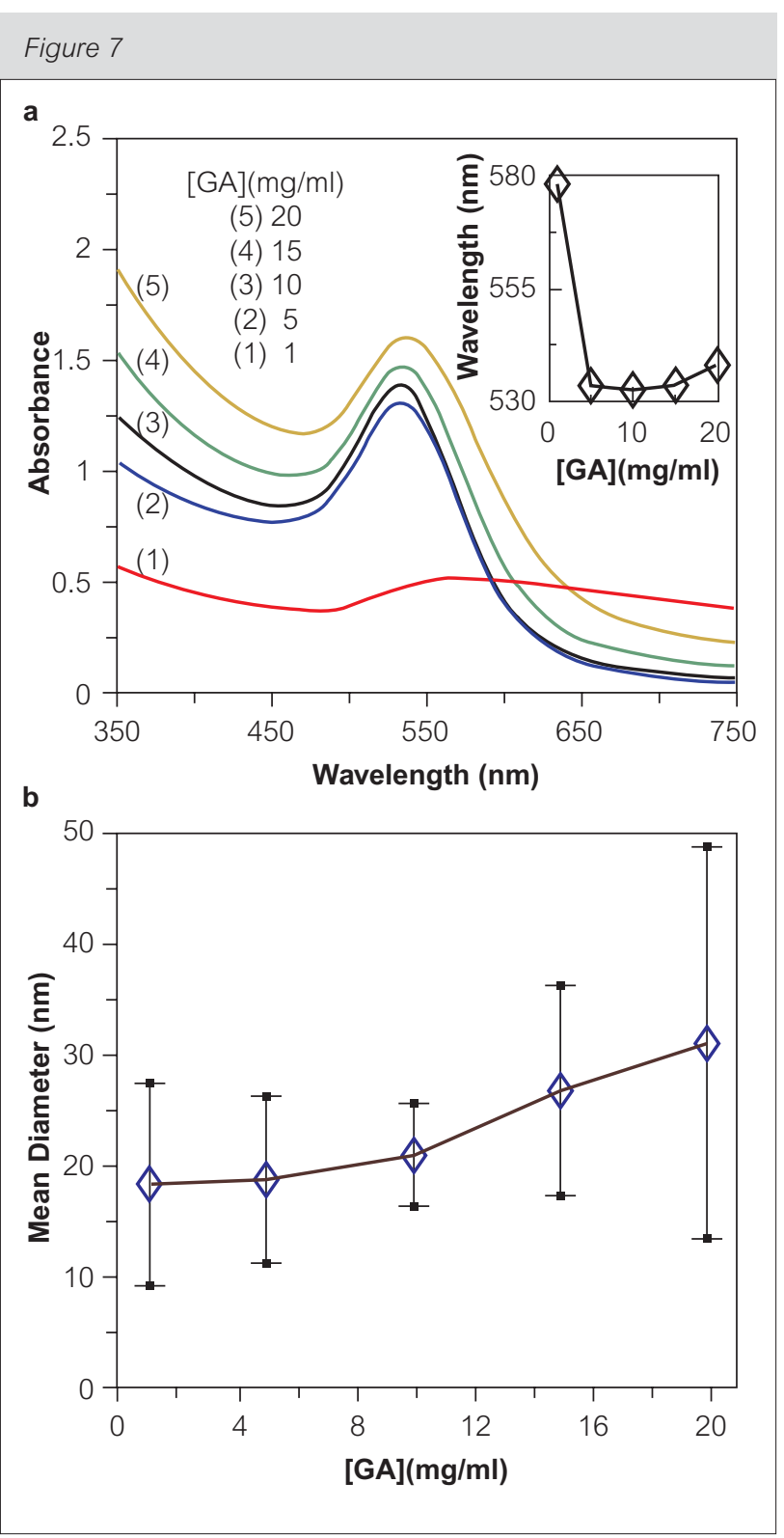

(a) UV-VIS absorption spectra of the resultant Au colloid solutions obtained at a Au(III) ion concentration of $0.3 \mathrm{mM}$, a temperature of $55^{\circ} \mathrm{C}$, and a reaction time of $4 \mathrm{~h}$ for various $G A$ concentrations. The inset indicates the effect of $G A$ concentration on the characteristic absorption band. (b) Variation of mean diameter with GA concentration 
concentration was not sufficient to reduce all Au(III) ions and stabilize the Au nanoparticles effectively. When the GA concentration was in the range of $5-20 \mathrm{mg} / \mathrm{ml}$, the characteristic absorption band of the resultant $\mathrm{Au}$ colloid solutions was red-shifted slightly with the increase in GA concentration (inset in Fig. 7(a)). The variation of optical property might be due to the difference in their particle size and size distribution. By TEM analysis, the effect of GA concentration on the mean diameter of $\mathrm{Au}$ nanoparticles was obtained as Fig. 7(b). It was found that the mean diameter of $\mathrm{Au}$ nanoparticles increased slightly with the increase in GA concentration. Furthermore, it was noteworthy that the particle size distributions were broader at lower and higher GA concentrations. The broad particle size distribution at lower GA concentration might be due to the insufficient protection by GA. At high GA concentration, the broad particle size distribution might be resulted by the increased intermolecular force of GA molecules which may hinder the dispersion of Au nanoparticles. Thus, insufficient or excess GA were unfavorable for the stabilization of $\mathrm{Au}$ nanoparticles. In this study, the optimal GA concentration was $10 \mathrm{mg} / \mathrm{ml}$.

\section{Stability of GA-stabilized Au nanoparticles}

The stability of the resultant Au nanoparticles was

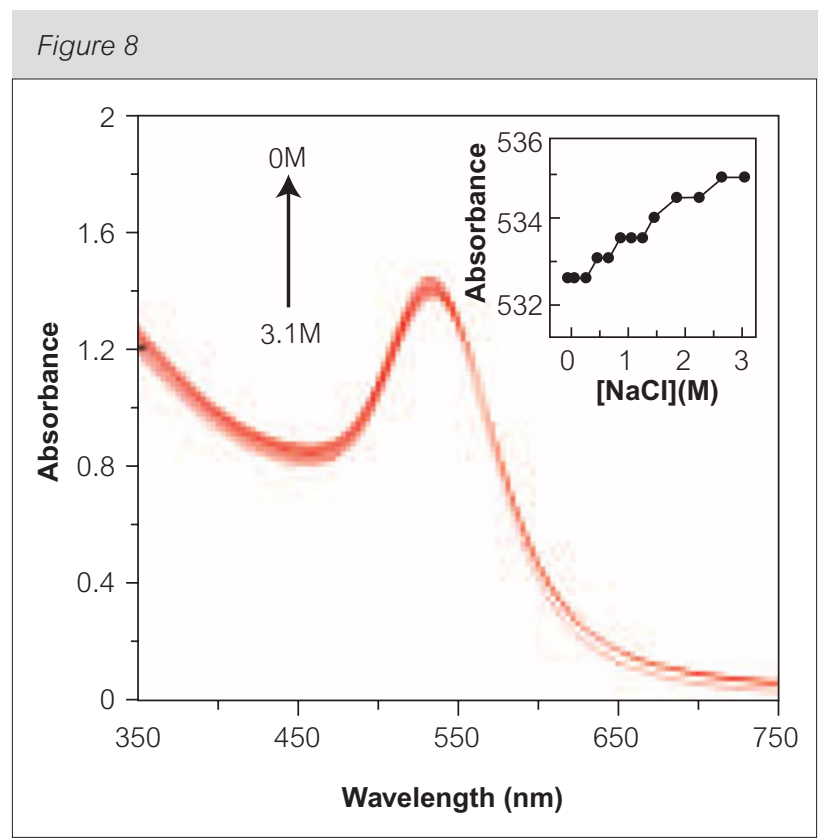

UV-VIS absorption spectra of the resultant Au colloid solutions obtained at a $\mathrm{Au}(\mathrm{III})$ ion concentration of $0.3 \mathrm{mM}$, a $\mathrm{GA}$ concentration of $10 \mathrm{mg} / \mathrm{ml}$, a temperature of $55^{\circ} \mathrm{C}$, and a reaction time of $4 \mathrm{~h}$ in the presence of various concentrations of $\mathrm{NaCl}$. The inset indicates the effect of $\mathrm{NaCl}$ concentration on the characteristic absorption band examined by a conventional electrolyte introducing method. It was found that the Au colloid solution remained quite stable in the presence of $\mathrm{NaCl}$. As shown in Fig. 8, when $\mathrm{NaCl}$ concentration increased from 0 to $3 \mathrm{M}$, the UV-VIS absorption spectra had no significant change and the characteristic absorption band shifted only slightly from 532.5 to $535 \mathrm{~nm}$ (inset in Fig. 8). Fig. 9 indicates the FTIR spectra of GA and the resultant $\mathrm{Au}$ nanoparticles. Both the spectra showed the main characteristic peaks of GA at 1049 and $1413 \mathrm{~cm}^{-1}$ (C-O stretch), $1612 \mathrm{~cm}^{-1}$ (C-O stretch and N-H bending), 2914 and $2995 \mathrm{~cm}^{-1}$ (C-H stretch), and 3000-3600 cm-1 (O-H stretch). Their similarity demonstrated the presence of GA on the surface of Au nanoparticles. Thus, the highly stability of Au nanoparticles could be reasonably attributed to the well protection of GA on the particle surface.

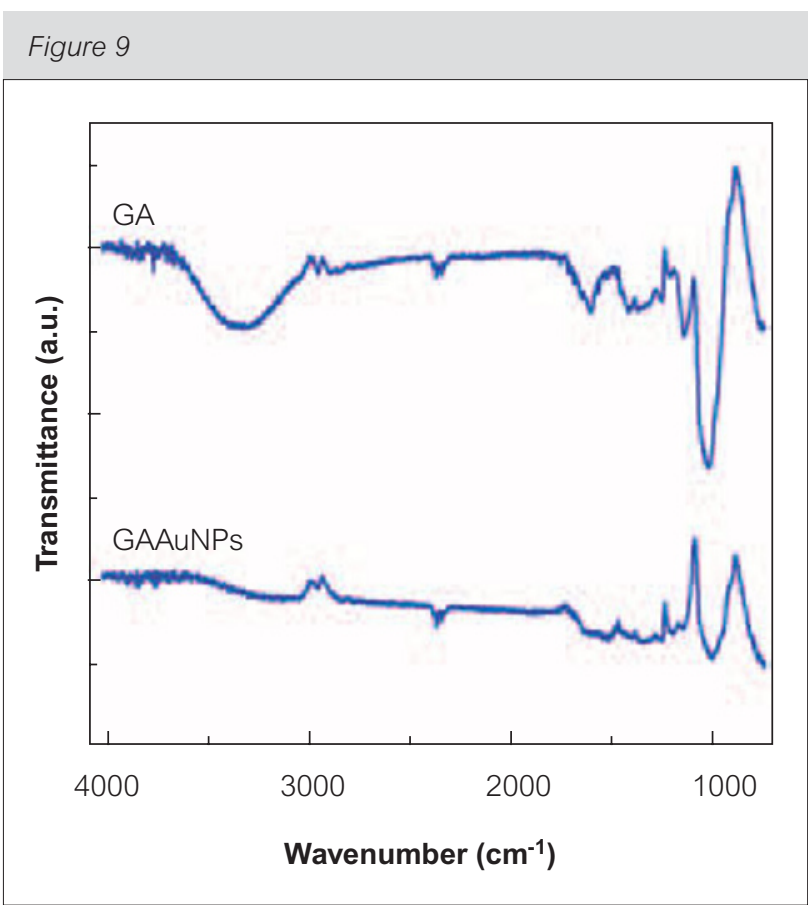

FTIR spectra of GA and the typical GA-stabilized gold nanoparticles (GAAUNPS) obtained at a Au(III) ion concentration of $0.3 \mathrm{mM}$, a GA concentration of $10 \mathrm{mg} / \mathrm{ml}$, a temperature of $55^{\circ} \mathrm{C}$, and a reaction time of $4 \mathrm{hrs}$

\section{Conclusions}

Highly stable Au nanoparticles with a fcc structure have been successfully synthesized at room temperature to a slightly elevated temperature by using GA simultaneously as a reducing agent and a stabilizing agent. The typical product obtained at a $\mathrm{Au}(\mathrm{III})$ ion concentration of $0.3 \mathrm{mM}$, a GA concentration of $10 \mathrm{mg} / \mathrm{ml}$, a temperature of $55^{\circ} \mathrm{C}$, and a reaction 
time of $4 \mathrm{~h}$ exhibited a characteristic absorption at $532.5 \mathrm{~nm}$ and had a mean diameter of $21.1 \pm 4.6$ and a mean hydrodynamic diameter of $26.8 \pm 5.3$ $\mathrm{nm}$. The synthesis reaction was usually finished in 2-4 h. With increasing the temperature from 25 to $75^{\circ} \mathrm{C}$, the formation rate increased but the resultant $\mathrm{Au}$ nanoparticles had similar optical property and particle size. Increasing $\mathrm{Au}(\mathrm{III})$ ion concentration led to slightly larger particle size or particle aggregation if GA was insufficient relatively. Lower GA concentration was not sufficient to reduce Au(III) ions completely and stabilize the Au nanoparticles, but too high GA concentration was also unfavorable for the stabilization of $\mathrm{Au}$ nanoparticles due to the increased intermolecular forces. In addition, the resultant $\mathrm{Au}$ nanoparticles were found to be quite stable even in the presence of $\mathrm{NaCl}$ up to $3 \mathrm{M}$ owing to the protection of GA on the particle surface. This work provides a facile, green, and cheap route for the synthesis of Au nanoparticles.

\section{Acknowledgements}

The authors thank the National Science Council of the Republic of China for support (NSC 97-2221-E$006-119-\mathrm{MY} 3)$.

\section{About the authors}

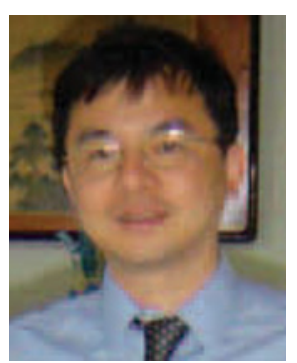

\section{Dr. Dong-Hwang Chen is a} distinguished professor of Chemical Engineering Department at National Cheng Kung University (Taiwan). His research works include the synthesis of nanoparticles, the fabrication of composite nanoparticles and thin films, the development of nanomaterials for electromagnetic wave absorption, as well as the fabrication and applications of functionalized magnetic nanocarriers in separation, catalysis, and biomedicine.

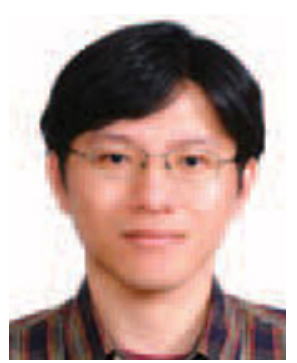

Mr. Chien-Chen Wu currently works as a PhD student in the laboratory of Prof. Chen in Department of Chemical Engineering at National Cheng Kung University (Taiwan). His research focuses on the synthesis and applications of nanoparticles and functional composite nanoparticles.

\section{References}

1 M. Daniel, D. Astruc, Chem. Rev., 2004, 104, 293

2 K. Kneipp, H. Kneipp, J. Kneipp, Acc. Chem. Res., 2006, 39, 443

3 M.T. Castãneda, A. Merkoçi, M. Pumera, S. Alegret, Biosensors and Bioelectronics, 2007, 22, 1961

4 T. Ishida, M. Haruta, Angew. Chem. Int. Ed., 2007, 46, 7154

5 A. Housni, M. Ahmed, S. Liu, R. Narain, J. Phys. Chem. C, 2008, 112, 12282

6 N. Higashi, J. Kawahara, M. Niwa, J. Colloid Interface Sci., 2005, 288, 83

7 S. Yokota, T. Kitaoka, M. Opietnik, T. Rosenau, H. Wariishi, Angew. Chem. Int. Ed., 2008, 47, 9866

8 R. Shukla, S.K. Nune, N. Chanda, K. Katti, S. Mekapothula, R.R. Kulkarni, W.V. Welshons, R. Kannan, K.V. Katti, Small, 2008, 4, 1425

9 S. Dhar, E.M. Reddy, A. Shiras, V. Pokharkar, B.L.V. Prasad, Chem. Eur. J., 2008, 14, 10244

10 Z. Zhong, D. Sim, J. Teo, L. Luo, H. Zhang, A. Gedanken, Langmuir, 2008, 24, 4655

11 S.K. Nune, N. Chanda, R. Shukla, K. Katti, R.R. Kulkarni, S. Thilakavathy, S. Mekapothula, R. Kannan, K.V. Katti, J. Mater. Chem., 2009, 19, 2912

12 P. Raveendran, J. Fu, S.L. Wallen, J. Am. Chem. Soc., 2003, 125, 13940

13 P. Raveendran, J. Fu, S.L. Wallen, Green Chem., 2006, 8, 34

14 J. Liu, G. Qin, P. Raveendran, Y. Ikushima, Chem. Eur. J., 2006, 12, 2131

15 C.C. Wu, D.H. Chen, Gold Bull., 2007, 40, 206

16 R. Bandyopadhyaya, E. Nativ-Roth, O. Regev, R. Yerushalmi-Rozen, Nano Lett., 2002, 2, 25

17 D.N. Williams, K.A. Gold, T.R.P. Holoman, S.H. Ehrman, O.C. Wilson Jr., J. Nanopart. Res., 2006, 8, 749

18 S.S. Banerjee, D.H. Chen, J. Hazard. Mater., 2007, 147, 792

19 S.S. Banerjee, D.H. Chen, Chem. Mater., 2007, 19, 3667

20 S.S. Banerjee, D.H. Chen, Chem. Mater., 2007, 19, 6345

21 D.V. Goia, E. Matijevic, Colloid Surf. A-Physicochem. Eng. Asp., 1999, 146, 139

22 V. Kattumuri, K. Katti, S. Bhaskaran, E.J. Botte, S.W. Casteel, G.M. Fent, D.J. Robertson, M. Chandrasekhar, R. Kanna, K.V. Katti, Small, 2007, 3, 333

23 M.E. Osman, P.A. Williams, A.R. Menzies, G.O. Phillips, J. Agric. Food Chem., 1993, 41, 71

24 K.K. Nishi, A. Jayakrishnan, Biomacromolecules, 2004, 5, 1489

25 S.K. Bhargava, J.M. Booth, S. Agrawal, P. Coloe, G. Kar, Langmuir, 2005, 21, 5949

26 Y. Shao, Y. Jin, S. Dong, Chem. Commun., 2004, 1104

27 K.K. Chia, R.E. Cohen, M.F. Rubner, Chem. Mater., 2008, 20, 6756 